
http://www.anpad.org.br/bar

\title{
Critical Management Studies: Some Reflections
}

\author{
Christine McLean* \\ E-mail address: Chris.McLean@manchester.ac.uk \\ Manchester Business School \\ Manchester, UK. \\ Rafael Alcadipani \\ E-mail address: Rafael.Silveira-2@manchester.ac.uk \\ UNINOVE and FGV-EAESP \\ São Paulo, SP, Brazil.
}

\begin{abstract}
This paper seeks to challenge some assumptions associated with Critical Management Studies (CMS). This is done based on insights originating from the Actor-Network Theory (ANT), an approach that can be considered as an empirical form of post-structuralism and that has gained prominence in social sciences. Fundamentally, this paper broadly reviews some key CMS ideas associated with this perspective ontology to argue that what CMS usually tends to take as explanation is exactly what has to be explained. Moreover, it discusses CMS' problematic view of objects and its tendency to neglect how existence is kept and maintained.
\end{abstract}

Key words: actor-network theory; critical management studies; organisation studies; post-structuralism.

Received 12 August 2007; received in revised form 02 January 2008.

Copyright (C) 2008 Brazilian Administration Review. All rights reserved, including rights for translation. Parts of this work may be quoted without prior knowledge on the condition that the source is identified.

*Corresponding author: Rafael Alcadipani

Rua Prof. Mucio Lobo da Costa, 191, Jardim Ana Maria, Jundiai/SP, Brazil, 13208-710. 


\section{INTRODUCTION}

Within CMS certain positions have been viewed as oppositional, in fact, the tensions among the different ontological and epistemological positions are seen by some as a crucial characteristic associated with the constitution of critique in MOS itself (Fournier \& Grey, 2000; Parker, 2002; Alvesson \& Willmott, 1992b). Thus, for Adler, there is no surprise that "too few of us would ever be able to agree on anything much" (Adler, 2002, p. 388), and for some, even the idea of Critical Management is perceived as an oxymoron (Zald, 2002). The constant clashes around what is a critical position in MOS (Fournier \& Grey, 2000; Thompson, 2004; Parker, 2002; Boje et al., 2001) has also raised questions concerning instances of inclusion and exclusion of some critical voices in the drawing of boundaries (Parker, 2002; Ackroyd, 2004).

In this way, critical analysis in MOS has been involved in a constant state of tension either when fighting against other non-critical positions or when facing arguments in critically inspired debates at academic meetings and in journals and special issues. Concerns raised include: the need to produce a continual stream of papers which reinforces certain positions (Hassard, Hogan, \& Rowilinson, 2001; Alvesson \& Willmott, 1992a), and sometimes a lack of in-depth empirical work (Collinson, 2002; Parker, 2002) Within this paper we are not seeking to engage in the debate of what constitutes critical studies in Management or to advocate one tradition over another, but rather to explore a range of important issues concerning certain assumptions that are more or less related to the CMS endeavour. In contrast, the main focus of the paper is to explore certain assumptions underlying the ideas that can be seen as unifying CMS, including how we account for the nature of existence. For instance, rather than advocating a stance that there is one single reality existing out there that can be more or less known or that can have different meanings inside the mind of different actors, the underlying idea here is that realities are constantly achieved, fabricated, enacted, and produced (Latour, 1997, 2005; Law, 2004). Gabriel Tarde addresses this issue in part by viewing everything as a society (Latour, 2001), and through his work on repetition and difference (i.e. to exist is to differ ${ }^{(1)}$ ).

For example, enacting CMS relies on main chains of associations relating to conferences, the division in the Academy of Management (AoM), special issues in journals, books, debates in the field, fieldwork, lectures, etc. Through these various enactments, different versions of CMS may be produced through a process of repetition and difference. However, how do you account for this process in terms of the specific ways in which we may refer to something (e.g. CMS) which is seen to extend in space and time, but which exists through many chains of associations which rely on multiplicity and alterity (otherness and difference)? CMS as all things (which always exist in some partial sense, as they are neither out-there or in the mind of humans) needs to be done, undone, redone and continually performed, and this creates and relies not only instances of homogeneity, but also heterogeneity. The next section seeks to commence this review by exploring a particular set of assumptions that might be more or less present in different CMS works, but could be seen as problematic in terms of engaging in a critical study. These are partly inspired by insights form the sociology of translation (Latour, 1982, 2002, 2004, 2005; Law, 1999a, b; Callon, 1986; Lee \& Hassard, 1999; McLean \& Hassard, 2004).

In so doing, this paper seeks to focus on exploring specific assumptions within the field of CMS. Certainly we intend to avoid falling into the trap of target homogenisation (Collinson, 2002) by evoking supposed typical and universal characteristics of what is to be critical in MOS or possible stances from which it would be possible to draw clear boundaries that discriminate the critical from the uncritical. This is particularly problematic in a field as complex and heterogeneous as critique in MOS. As we have implied above, we wish to avoid a view of MOS critique as a more or less stable object existing out there that has inherent $a$ priori characteristics, or a reliance on some form of abstract notions that seem to exist inside minds. Rather, this paper advocates a view of CMS as outcomes of different enactments that must be understood in their full complexity, heterogeneity and diversity. As such, critique in MOS is done, redone, undone, maintained, performed and produced during such a process. In accordance with what we have stated above, existence is related to imitation 
and difference. Therefore, we do not defend that the underlining assumptions we discuss below are necessarily present in every single CMS account. Instead of that, what it might be possible to say is that they are more or less present in CMS enactments as the critiques themselves do not only rely on difference, but also rely on imitation. According to Gabriel Tarde, imitation is a key process when it comes to understanding societies. Rather than seeing imitation as a simple mechanical copy, it is perceived as an adaptation of one idea or action. As a result, every adaptation is different from another. Thus, imitation also implies transformation (Czarniawska, 2004). In the remainder of this section, we will explore and discuss what can be seen as the underlining assumptions of CMS.

\section{Problematizing CMS}

This section seeks to review the hasty reification of social explanations and parameters which are seen to act upon setting. For example, an excerpt from the CMS division at AOM outlines what is viewed as the underlying basis of CMS: "Our premise is that structural features of contemporary society, such as the profit imperative, patriarchy, racial inequality, and ecological irresponsibility often turn organizations into instruments of domination and exploitation”(2). Furthermore, Adler suggests that critical MOS seeks to use theoretical traditions to "help us understand the oppressive character of the current management and business system” (Adler, 2002, pp. 387-388). In a similar fashion, Grey (2005) points out that

CMS represents the possibility of drawing together those elements within business schools (and cognitive areas) who share some oppositional tendencies. That is: oppositional to established power and ideology; to managerial privilege; to hierarchy and its abuse; to put it at its most generic, not only the established order but the proposition that the established order is immutable (Grey, 2005, p. 12).

Grey highlights that this statement can of course have terms included or deleted, but stresses that to do so "is to fail in the most self-indulgent and irresponsible way, to understand either the possibilities or the frailties of CM” (Grey, 2005, p. 12).

We do not suggest that all those who would view themselves to be CMS scholars would necessarily sign up to all these aspects. However, there are many occasions of accounts (which could be viewed as under the CMS umbrella), which would focus on denouncing the oppressive, and negative characteristics of management, business systems and our world. Are the facts of reality perceived by critique as more or less clear? The focus on what is wrong with this reality often originates in theoretical tools relating to power and/or ideology, oppression, inequality, hierarchy etc. These being perceived as the basis, the panacea, upon which to explain a range of management problems in our society.

In other words, this oppressive and negative character appears to exist in some given and/or constructed form, created by opaque social forces, such as power, domination and ideology. Do we need to attend further to how we view such dominations, oppressions, inequalities, etc., with regards to the various enactments and circulations, and do we limit our understanding by focusing on a specific phenomenon (e.g. inequality, domination, oppression, gender etc.) as the source of the explanation? In this way, what are the problems associated with substituting the complexity and uncertainty of entities and relations with a standardized non-problematic parameter (e.g. capitalism, power, identity etc.), as a form of explanatory device. By focusing on how these social aspects act, do we fail to account for the specificities, heterogeneities and complexities (Latour, 2002, 2005) and, once defined, are these parameters assumed to be present almost everywhere and acting behind the scenes, being able to explain a plethora of other circumstances? For instance, power, ideology, capitalism, etc., are used to explain problems from worker resistance (Thompson, 1983) to issues of global domination (Hardt \& Negri, 2000), to name but a few. 
Generating the hasty reduction and rarefication of acceptable entities in accounts can be particularly problematic especially as such perspectives often claim to focus on emancipation (Latour, 2005) and seek to give voice to silenced victims. This could be seen as creating sociological accounts as blank figures that fit into different ordering process depending on what is needed to establish an account (Hetherington \& Lee, 2000). As a result, the practical means by which events are produced and circulated are not fully explored (e.g. power, domination, ideology, to name but a few) and what must be explained is left unexplained, with all pluralities and complexities associated with them vanishing (Latour, 2002, 2003, 2005).

In seeking to examine how courses of action appear to enter social ties following a critical perspective, Latour highlights three main modes of existence: a material infrastructure that determines social relations (e.g. some Marxist forms of materialism): a mirror that reflects social distinctions (e.g. Bourdieu's analysis); and a frame where human actors play the main roles (e.g. Goffman's interactionism) (Latour, 2005). Thus, rather than analysing the pluralities of participants in different courses of actions, Latour suggests that critical sociologists might provide standardised ways of addressing and explaining ordering process, with a repertory of explanations already made. When what they are is not addressed, how they are kept and maintained, we may fall into the trap of reproducing over and over again the same repertory without addressing in more detail this problem of explanations existing in some opaque and standardised form. For instance, power can sometimes be projected as an invisible social force, a key actor behind the scenes creating certain effects and outcomes. This relates to various applications of CMS to different degrees, and the application of ideas underlying the work of Michel Foucault within CMS are not insulated from the problems of viewing power as a driving force acting behind the scenes. Rather than having a theory of power, Foucault refers to an analytic of power relations. He suggests that power is an outcome of practices, the final result of a process, not what is behind causing events. For instance, discipline is an outcome of practices of imprisonment analysed by Foucault, and governmentality an outcome of certain practices of government. Thus, power relations in Foucault's understanding are a very complex result of specific practices that can not be a convenient source (Knights, 2002) of theory that can be trapped into theoretical definitions as something to be applied and reapplied over and over again in almost every organisation by well informed researchers. Quite the contrary, power has to be produced, reproduced and performed and should not be taken for granted. By focusing too heavily on power in such a way we may lose a sense of heterogeneity and often within accounts power does take on much more of an explanatory role. This also relates to discussions of standardising what is critique, especially where parameters regarding what it is to be critical and what is not are viewed as unclear and problematic (Thompson, 2004). In addition, Ackroyd (2004) argues that many post-structuralist perspectives in CMS are often grounded on a moralising stance that evaluates what kind of critique is acceptable and what is not, what voices are allowed to speak and what must be kept in silent. However, a similar argument could be directed at many approaches under the CMS banner and relates to the impact that the form of critique and practices of enunciation (Jones in Boje et al., 2001) have on issues of articulation, accounting, and silencing.

\section{FACTS AND FETISHES}

Critique is described by some as playing "a crucial role in identifying and clarifying the big issues of life" (Willmott, 1995, p. 42). Do CMS scholars have some special and peculiar kind of knowledge which makes then more able to reflect on issues others cannot. When reflecting on her own experience, Gherardi (Boje et al., 2001, p. 310) claims that "we learned very easily the rhetoric of being critical. We learned the tricks of the trade (...) you learn how to do it, then it does not matter to what you apply it”. When referring to critical thought, Latour (2005) ironically suggests that such training seems to guarantee borderless vision, the possibility of endless understanding of an actor's behaviour from above. Occasionally, actors are often seen as being in need of enlightenment regarding the frame they inhabit in order to secure some form of emancipation. Discussion about emancipation is 
animportant aspect of CMS (see Alvesson \& Willmott, 1992a; Alvesson \& Willmott, 1996) and deciding: what is correct and what is not, what kind of practice leads to emancipation what does not, how individuals are trapped in a particular context, what the real causes of their actions, behaviours are, etc., is often placed in the hands and minds of highly trained CMS scholar. For Latour, most critical scholars can never fail but to be right (Latour, 2005).

You are always right! When naïve believers are clinging forcefully to their objects, claiming that they are made to do things because of their gods, their poetry, their cherished objects, you can turn all of those attachments into so many fetishes and humiliate all the believers by showing that it is nothing but their own projection, that you, yes you alone, can see. But as soon as naïve believers are thus inflated by some belief in their own importance, in their own projective capacity, you strike them by a second uppercut and humiliate them again, this time by showing that, whatever they think, their behaviour is entirely determined by the action of powerful causalities coming from objective reality they don't see, but that you, yes you, the never sleeping critic, alone can see (Latour, 2003, p. $6)$.

Thus, informants are perceived as rather passive participants, not able to truly reflect on the situation in which they are located, unable to see the whole picture (even though the form this picture takes is questionable) and unaware of the indisputably real and hidden social forces which guide their actions. In this sense actors can appear as blind victims who are trapped by such invisible social forces. These forces have the dual character of appearing visible to the highly trained CMS scholars, but opaque in exploring the detail and complexities underlying such forces. It becomes viewed as something out-there, the source of the explanation, rather than something that requires explanation, and relies on particular versions of how we view existence and agency (Latour, 2003, 2005). For instance, Empire (Hardt \& Negri, 2000) and hegemony (Gramsci, 1971) are examples of social forces that act upon passive actors who are almost unaware of their existence. The forces are taken for granted in the order of things and as socially producing and reproducing their effects, and it is left to the CMS scholars to uncover these forces and to open their eyes to the consequences they create.

Latour (2003) also links some forms of critical thought to conspiracy theory, as he suggests that in both cases it is necessary to be suspicious of everything that people say, certain people are unaware of what is happening, and there is some overarching force which is seen as a driving force in terms of outcomes and effects. Furthermore, in both cases a relatively small number of agents are viewed as knowing the truth and possessing the capacity to reveal it to everybody else (Latour, 2003). For Latour, critical thought is not only based on a contradictory repertory, but it also decides a priori which entities are allowed to occupy and compose the social world and overlooking the agency of those entities that are considered blind, or in a state of illusion, together with certain other entities which inhabit the world.

For instance, this god-like ability to do reflexively what their informants do not, is further exacerbated by the fact that the source of this reflection stems from information provided by apparently blind informants (i.e. the opaque social forces and blind actors). This reflexivity could be viewed as a selective blindness. In Latour's words, what is positioned as reflexivity often involves a "sheer irrelevancy of questions raised by the analyst about some actors" serious concerns (Latour, 2005, p. 28) and "a way of asking totally irrelevant questions to people who ask other questions for which the analyst does not have the slightest beginning of an answer!” (Latour, 2005, p. 132). For example, meta-narratives of modern CMS perspectives in MOS assume the validity of their own truth claims, generating theoretical models that have no grounds on which to assert their own claims over alternative ones. Is there the assumption that CMS theorists arbitrarily know the ultimate truth (real or constructed) (Shayne \& Humphries, 1997; Parker, 1999; Clegg, 1994)? In other words, what is known is decided even before the questions are asked (Clegg, 1994) and this acts as a self-fulfilling prophecy, and for some this process aligns certain work which could be described as post-structuralist inspired to positivism (Wray-Bliss, 2002). Additionally, concerns have been raised that in some post-structuralist inspired analysis, the empirical evidence seems to be lacking when compared to the strong claims imposed (Thompson, 2004; Armstrong, 2001), and others suggest that some papers appear to fit the 
evidence to the theory, which merely serves to reinforce this self-fulfilling prophecy (Armstrong, 2001).

\section{ObJeCtS AND CRITIQUE}

So far we have pointed out that the problem of CMS thinking in part sustains itself by maintaining two positions that are never considered together. First, certain objects are viewed as simple fetishes (those they do not believe in within that part of their analysis, such as religion, arts, politics, to name but a few). Second, other objects are hastily reified into matters of fact (i.e. invisible forces acting behind the scenes such as the social, economy etc.) (Latour, 2005). Concerning the issue of objects, there is also the problem of how what could be considered as non-humans are positioned in relation to humans and the role they are seen to play in many CMS accounts (e.g. with limited exposure, mere consequences of social forces, or sometimes appearing for moments as that which determines social action - Latour, 1988, 1992, 2005; Law, 1991). In other words, even when non-humans do emerge as actors, they adopt the role of agents of social change determining outcomes, or play supporting roles backstage. For Latour:

That society is unequal, hierarchical, that it weighs disproportionably on some instead of others, that it has all the character of inertia, that domination breaks down bodies and souls, is one thing: to conclude that these hierarchies, dissymmetry, inertia, powers, cruelties are made of social stuff is a different argument all together. Not only the second point has no logical continuity with the first, but it is also, as we shall see, in complete contradiction with it. In the same way as the overtaking of action by other agencies does not mean that Society is taking over, the flagrant asymmetry of resources does not mean that they are generated by social asymmetries. It just lead to the opposite conclusion: if inequalities have to be generated, this is a sure proof that other types of actors than social ones are coming into play (Latour, 2005, p. 55).

This relates to the idea that if issues such as power, domination, oppression, inequality, etc. are to be addressed, it is also necessary to take into account the vast array of non-humans that are also present and are part of them. Clearly, some work in MOS has sought to take non-humans into consideration in a more symmetrical way (Organization, 2005). However, these interpretations of ANT can range from some very insightful developments to rather problematic applications. Moreover, the problems of ontology, especially when addressing issues of power and CMS thought, still remain.

\section{RECONSTRUCTING THE SOCIAL: THE CONTRIBUTION OF ANT}

The aim of this paper so far has been to explore some of the assumptions that more or less underlie enactments of CMS thought. This is not an attempt to undermine the critical desire to tackle complex issues of inequality, social justice, hierarchical divisions, exclusions and colonialism, to name but a few, intentions with which we are strongly sympathetic. However, a fight against invisible forces located behind the scenes that have existence in a partly occupied social world could be seen as high price to pay. It is also important to note that this paper does not address the questions posed by a CMS theorist who wishes to find practical ways of tackling issues of domination, power and control in a direct and instantaneous way. To study this issue of politics and domination which are always complex and heterogeneous requires a more sophisticated understanding of ontology and methodology which avoids a quick fix and provides a detailed analysis of issues without short circuiting and too quickly resorting to explaining aspects away. Quick fix explanations in a number of cases lead to the silence of complexity and heterogeneity, with assumptions of reality and existence in a simplified form, and certain entities and relations being disregarded. 
As discussed above, it is clearly problematic to assume existence as being out there whether it is in an essential, natural or socially constructed form. Equally so is the process of deconstructing everything until we have nothing. However, how can we understand existence that avoids a reliance on some form of solid entity, or abstract notion of social construction or deconstruction? Let us first see how ANT has sought to overcome certain problematic assumptions explored so far within this paper.

Through its "ruthless application of semiotics" (Law, 1999b, p. 3) ANT seeks to focus on relations and associations in order to explore in greater detail outcomes and effects. In so doing, this perspective avoids the commonsense assumption that people, tools or machines are natural categories. Reality has neither a stable nor a definitive status: it is neither out there nor in here, and is formed by associations of heterogeneous materials composed by humans and nonhumans alike bound together. For Latour, "Nothing becomes real to the point of not needing a network in which to upkeep its existence" (1991, p. 118). Certain chains of associations can be more real and enacted as more stable than others (Law, 1992). However, how do these associations come to exist and in what form? Within this remaining part of this section we will attempt to explore these issues in relation to the ideas of construction and performance.

Generally, to say that something is constructed means that it is "socially constructed", made of "social" stuff - "a kind of fabric to account for the fabrication of facts" (Latour, 2002, p. 2) which is often human centred. Furthermore, to be constructed is viewed as not real as construction is perceived in opposition to reality (Latour, 2002, 2004, 2005). This notion of reality is clearly problematic and we need to reconsider our versions of constructed and real in order to make more sense of this process. For instance, construction can involve many different ingredients, subtle co-ordinations and mobilisations, and continuous associations (involving both humans and nonhumans), and what is considered "real" is enacted through such mediations (Latour, 2005).

An advantage of engaging in the research in such a way is that it is possible to focus on the great deal of work and mediation (e.g. associations of humans and non-humans) underlying this process. Moreover, according to Latour (2004) certain principles often underlie such an analysis. First, the idea that the realities to which humans are attached depend on a series of mediations, and that both mediators and realities are made of heterogeneous mediators that have their own stories. For instance, how many process, interactions, discussions, elements, etc., are involved in constituting and maintaining power relations, dominations or inequality? Second, the amount of heterogeneous mediators and the number of mediators necessary to sustain realities are a credit to their reality. Often, the more mediated it is, the more real it becomes. Third, our realities are open to differing interpretations that must be considered with caution. Fourth, if a reality extends in space and time, this relies on the extension of its complex life-support systems. Finally, realities require careful maintenance and repair - and some may fail (Latour, 2004).

Those points are related to the idea that the process of construction is never over. For instance, to exist, a building has to be under a continuous process of being made and remade, done, redone and undone. The same is true of a vaccine. For example, it works through reproducing the laboratory conditions (Latour, 1993) and engaging alterity. In both examples it is possible to realise the amount of work and activities that have to be carried out in order for assemblages to exist (Latour, 1997), as to exist in whatsoever form, assemblages have to be constantly made and remade. As a consequence, associations are always performed as - "the object of a performative definition vanishes when it is no longer performed" (Latour, 2005, p. 32), and they are interdependent on other associations that interact and intersect with each other. For many it comes as no surprise that to exist relies on this continual performance and remaking. For example, capitalism is preformed in every corner; to exist it requires a great deal of work, actions and processes to be carried out at every moment, and performing order and control relies on complex systems. To be constantly performed, deployed, and redone involves a great deal of work and circulations. Also, CMS or critical perspectives in MOS are constantly made and remade. During the 1980s, to be critical in MOS was associated with LBT, however, nowadays traditional LBT may feel excluded in terms of CMS (Ackroyd, 2004; Grey, 2005). 


\section{Entities, Associations AND Groups (AS ACtOR Networks)}

ANT has therefore sought to highlight the importance of studying how connections are established, how associations are made and unmade, relations between entities, and how assemblages and facts emerge as outcome of such process. To say that a fact is constructed "means that we account for the solid objective reality by mobilising various entities whose assemblage could fail” (Latour, 2005, p. 78). The danger here is to assume that once entities are constructed they can appear as existing out there. Instead of entities existing in an a priori form out there or in here, they need to be viewed as constantly achieved through a complex and constant process of construction. This involves not assuming which kinds of entities are allowed in accounts and the form they take while also taking into account issues of homogeneity and heterogeneity. For example, what may account for control may be enacted differently through alternative chains of associations. Thus, it is always a matter of empirical investigation to understand events, and each account relies on a detailed examination of certain circumstances in specific settings.

By exploring this process of construction and enactment it is possible to examine such aspects without paying the price of fighting against some hidden social forces. This entails addressing issues of durability, continuity, etc. with regards to this complex construction and helps to overcome the problematic view of objects within accounts. In addition, in exploring how realities are enacted in such a way, actors are not viewed as blind victims of hidden social forces, and boundaries such as inclusion /exclusion become outcomes of the process (Bijker \& Law, 1992; Law, 2004; Latour, 2002, 2005) and are performed through the constant movement, construction, enrolment and formation of different groups, as long as a plethora of different and contradictory groups are constantly made. For example, Law (2004) uses the 2001 epidemic of foot and mouth disease in the UK to address how exclusions and boundaries are fabricated. In relation to the issues of contamination, strong barriers between affected and non-affected regions were constantly enacted (e.g. zones described as disease free) and well-articulated in part through various institutionalised apparatus of administrative, legal, veterinary, customs etc. Each of them relies on many assemblages bound together that enact such boundaries between those different places, and while animals from disease zones are excluded from disease free places with huge economic consequences to the former, it is important to understand this in relation to these complex chains of associations. In fact, foot and mouth disease is not the only illness that affects foreign commerce from third world countries. The same happens to soy, oranges and chickens, to name but a few, and many questions are raised concerning the enactment of such boundaries (e.g. commercial protectionism rather than with health and safety issues).

For Latour (2005), it is clearly important to follow the actors and/or the traces left behind the actors' activities during the creation and maintenance of groups, rather than advocating a perspective in which groups are formed before engaging in empirical research (e.g. what kind of group and level will be addressed). There is a need to focus on the controversies relating to groupings, not in a search for some unique truth, but rather to account for the different associations and explanations underlying the production of accounts that help to sustain realities. Moreover, it is important to highlight the impossibility of having a total view of associations from one place. Moreover, when groups are made to talk, anti-groups are mapped (Latour 2005), and his may involve spokespersons (e.g. spreadsheet model, advocate etc.) which contribute to the process of defining who and what the group has been, is, and will become. The production of such accounts feed from group formation disputes and other controversies around what a group is, what it should be, how it must operate, etc. As a result, scholars, rather than being located above everything else understanding what actors cannot, are located alongside actors in the creation and performance of groups.

In this sense, there are always actors at work, justifying the existence of a group and trying to draw its boundaries. However, most of time and in the majority of cases, enactments differ and variations occur even though something may remain which we refer to within such enactments. For instance, the arguments surrounding what is to be critical what is not in MOS, the different positions on the LBT 
debate, and the discussions concerning post-structuralism and modernists provide examples of controversies around group formation. While some may argue that CMS has fairly clear boundaries (Fournier \& Grey, 2000; Alvesson \& Willmott, 1996), for others, these boundaries are seen to silence the voices of other critical approaches (Thompson, 2004; Ackroyd, 2004). There is not a correct account of what is critical in MOS and any definition is open to be question (Hassard et al., 2001). However, it would be interesting to study the various enactments surrounding CMS.

Thus groups are produced and performed by a great deal of work and mediations. This relates to ideas of repetition and differences (e.g. groups being contrasted to anti-groups, but also the role of many different entities and the process by which collectives are formed and deformed, creating further instances of durability and difference). To examine such a process requires much in-depth empirical investigation (e.g. exploring the various forms of traces between different entities and what kind of assemblages have been established to produce such effects). Thus, achieving stability is something which is both costly and demanding (Latour, 2005) and relates to many instances of multiplication and difference. For groups, like all things, are performed and have to be done, redone, and undone. This performative stance has the consequence of making the case that groups are performed in many ways to exist, but are never totally done. As a consequence, boundaries and inclusion/exclusion are effects of group formation and development, and are always open to change. In other words, exclusion and boundaries are performed in so many different ways by different and juxtaposed assemblages that overlap one another, constructing certain differences between what is inside and what is outside. Those assemblages are kept, maintained, fabricated, controlled, and negotiated by the continuous performance of process and practices (Law, 2004; Latour, 2005). It is clearly problematic to accept that this complex process can be explained by simple standardised notions, or by some hidden social force, which is both the cause and consequence at the same time. Inclusions/exclusions are not given; they are produced by an array of complex assemblages bound together. As a result, they cannot be explained by simple cause-effect models that assume dark forces as the main actor in generating exclusions. However, if these forces are not the explanation, who or what is acting? How do we understand these issues of responsibility, accountability and agency? How can we address agency without regarding it as a simple effect or attribute of hidden social forces and/or the exclusive attribute of humans?

\section{ACTION AND AGENCY}

Rather than relying on the human actor as fully in command, construction within ANT implies that agency is distributed among a plethora of actants over which there is no single control or mastery (Latour, 2002).

I never act; I am always slightly surprised by what I do. That which acts through me is also surprised by what I do, by the chance to mutate, to change (Latour, 1999a, p. 281).

Thus, ANT does not regard action as an exclusive feature of humans. It argues that nonhumans also act in very practical circumstances (Latour, 2005). For instance, differences exist between zapping TV channels with or without a remote control, travelling with or without a car, producing an academic paper with a PC or a typewriter. To be able to calculate and make choices, Latour (2005) argues that we take advantage of measurement instruments and equipment (e.g. as a consumer we rely on labels, trademarks, advertisements, prices, indexes, measurement units and TV programmes, to name but a few) and Law (1996) illustrates how a manager relies on a vast array of non-humans such as files, computer systems, telephones, mobile phones, fax machines, data etc. Action should therefore be seen as shifted and delegated to different types of actors that have the capacity of transporting it farther, and this transportation involves the presence of humans and non-humans in the same collective. In other words, action is only possible in collectives. This does not mean that non-humans determine cause or impose actions. Quite the contrary, "things might authorize, allow, afford, encourage, permit, suggest, influence, block, render possible, forbid, and so on” (Latour, 2005, p. 61). To neglect the role played 
by nonhumans in the process of maintaining inequalities, exclusions, domination, etc. generates the reduction and rarefication of acceptable entities in accounts (Latour, 2005), which seems contradictory to a perspective that seeks emancipation (Latour, 2002, 2003, 2005).

Rather than being the source of action, an actor is therefore "the moving target of a vast array of entities swarming towards it” (Latour, 2005, p. 39). The key idea underlining this notion is that one actor is never alone while acting and "action is borrowed, distributed, suggested, influenced, dominated, betrayed, translated" (Latour, 2005, p. 40). Action could be seen as overtaken or othertaken.... "taken up by others, shared with the multitudes, the masses mysteriously carried out at the same time and distributed too many others" (Latour, 2005, p. 38). Furthermore, while agency requires some form of movement, change or transformation, different figurations may be created to account for it, different theories of action used to explain the effects of agencies, and through this process, some may attempt to problematise or disqualify certain agencies. The question shifts to how to follow the traces and consider these agencies not as matters of fact, but as matters of concern, in order to examine the various modes of fabrication and stabilising mechanisms. Therefore, we need to feed from controversies over agency (Latour, 2005), as action and the attribution of agency is the result of the continual process of translation, connections, negotiations and the assemblage of different and complex entities (Latour, 1999a; De Laet \& Mol, 1998; Gormat \& Hennion, 1999; Law \& Moser, 1999; Michael, 1996; Callon \& Law, 2004). One way of addressing this issue of action and agency is via the overflowing of interactions with the many different ingredients, coming from other times, spaces and actings (Jones, McLean, \& Quattrone, 2004).

The assembling of these many other local interactions which are distributed elsewhere (via timings, spacings and actings) occurs via diverse sets of relays and chains of associations. For Latour (2005), these localities are not given in the order of things as they rely on articulators or localizers who engage in this continual process of assembling and redistribution. While localizing enables such dislocated actions to act through indirect associations and circulations, this also produces instances of multiplying in the sense of creating more openings and closings. Accounting for this fabrication process relies on alterative ways of conceptualising such orderings. In particular this relates to an avoidance of centring and an excessive desire for coherence in which stability and multiplicity cannot easily co-exist or overlap. Key to our understanding of such issues relates to our view of interactions, circulations, absences, and entities such as localizers. For instance, as Latour notes, interactions should not be viewed as isotropic or isochronic, as time and space are always folded, even if they may produce effects of isotropy or isochrony. Secondly comes the issue of visibility and tracing, as few participants may be visible in a course of action at the same time. In other words, interactions are not synoptic, and by viewing everything from one place fails to account for the issue of multiplicity and shifting agencies (i.e. there are no homogeneous interactions as actions are never carried out by the same material throughout). Thus, interactions are not homogeneous and participants may exert different kinds and quantities of pressures (i.e. interactions are not isobaric). Understanding issues of quality, quantity and effects are important aspects to consider. Consequently, it is imperative that we gain an insight into entities, interactions and shifting agencies which are not always visible in the same time or place, do not exert pressure equally and can lead to different outcomes in terms of stability and multiplicity (Latour, 2005); thus, places/entities could be seen as framed by actions/agencies coming from elsewhere, and this requires an alterative view of organizing in relation to this issue of space and time, as well as an understanding of durability and difference.

When reflecting on issues of durability and difference it is necessary to avoid relying on a view of space and time as given in the order of things, as spaces and times are also fabricated through this process (Jones et al., 2004). Latour (2005, p. 1997) argues that nothing travels without chains that sustain them and this requires the support of many entities to exist (e.g. laboratories, knowledge, discourses, control etc.). By gaining an insight into the various interactions and connections (including their strength and fragility) we can focus on this continual process of fabrication. For instance, Latour describes how, "scale does not depend on absolute size, but on the number and qualities of dispatchers and articulators" (Latour, 2005, p. 172) and thus rather than seeing the local and the global as given aspects, issues such as scale and size should be seen as achievements (Callon \& Law, 2004). In other 
words, we should not assume that one place is bigger than another, and in contrast we should focus on how some are seen as benefiting from safer connections with more places than others (Latour, 2005, p. $155)^{(3)}$. For instance, how does the number and character of the many connections relating to something like Wall Street make it both constructed and real, and more important than other localities (Latour, 2005).

\section{Discussion: Mediations, Assemblages And Political TalK}

How do we analyse all the work and mediations involved in achieving stability and multiplicity without explaining it away via hidden forces existing behind the scenes or relying on some solid form existing out-there. The establishment of size, presences and visibility through the traces that the construction work leaves behind plays an active role in creating presences and absences (e.g. in creating what can be seen and what cannot, or what can be accounted for, and what cannot). However, connections, conduits, tubes that perform size and visibility, that keep things existing through difference and repetition, are not always fully visible. As discussed previously, what is visible in one account may be invisible in others, and accounts can never be total or universal (e.g. seen from one place). In fact, absences also can act (Law \& Mol, 2000; Hetherington, 2004), and may play a key role in producing the object which is never unique and simple (Law \& Singleton, 2005)

Clearly, we need to address this issue of what explains and what has to be explained, the directional forces of social action, how certain practices and entities are seen to travel and extend in space and time while others appear to diminish and fade, and that rather than focusing on homogeneity and durability, we should understand stability and change in terms of difference and otherness. Through doing this it might be possible to understand better the political aspects that interest CMS scholars (e.g. inequalities, inclusions and exclusions) and how they are constructed and fabricated. In this context, the traditional notion of politics may be of little help and may underestimate the difficulty related to doing politics by insisting that the social consists of a few participants, and a rather restrictive a priori list of welcomed members making up the social world. To modify a state of affairs, it is necessary to take into account that forces are made of different ties and it is necessary to render politics important again by tackling the question of assembling with these participants that they have put aside (Latour, 2005). For any political project, it is necessary to readdress this balance and this involves exploring the different ties associated with the assembling the Collective or the Body Politic (Latour, 2005, p. 226). For Latour, a key target is to analyse the stabilizing mechanisms that prematurely transforms matters of concern into matters of fact, and this includes those that make the deployment of actors visible, and secondly, the procedures that make the unification of the collective into a common world acceptable by those who are unified. This relates to the idea of the shift back from intermediaries to mediators, and a need to focus on the various regimes of enunciation within specific fields of study (e.g. science, law, religion, economics, art). Therefore, in order to retrieve the dynamics and specificity of politics (particularly the role in the making of collectives with regards to the fragile and temporary construction of social aggregates), part of the solution for Latour lies in studying regimes of enunciations (Latour, 2002). This includes the unfolding of mediations peculiar to particular fields of study, such as what is at play when one talks to someone about something in a political way? While acknowledging that politics, law, art and religion, to name but a few, simultaneously belong to all enunciation regimes, for Latour, it is necessary to suspend this thought in order to focus on particular regimes of talk and manners of speech.

In the case of politics, while talking political may be viewed positively, it is often associated with negative connotations, something which slows things down, evades direct action, produces extra factors to consider and labour over, and involves deviations from faithful information and representation (Latour, 2002). There is a need to abandon the assumption of the guaranteed existence of groups and rather focus on how they are continually formed through re-grasping them, enveloping them in the curve of political talk. The role of enunciations is key to this process and by separating 
them we no longer see the point of political talk (Latour, 2002, p. 5). For instance, uttered talk does not belong to those who say it, and the identification of origins in terms of which other agents are involved in the process of talk is clearly a political issue. The continuous presence (and absence) of these others, in the form of the irreducible multiple or their indispensable unification, partly accounts for the slowness and curvature of political talk, but also the ways in which issues of authorship and authority are consubstantial to political ways of talking especially in terms of identifying in the name of whom we are talking (Latour, 2002, p.13).

Consequently, within this paper we have sought to highlight the problems with assuming existence to be out there (whether it is in an essential, natural or in socially constructed form), but we also wish to avoid a process of deconstructing everything until we have nothing. When engaging in studies of political aspects, how can we understand existence that does not rely on some form of solid entity, or abstract notion of social construction or deconstruction? The definition of organization provides a good example of highlighting the problem of focusing on outcomes of homogeneity and order. It is clearly problematic to define an organization in terms of what it is, but how do we understand it in terms of what it is not, and what it can potentially become (Jones et al., 2004). Clearly we wish to avoid the exclusion of diversity in terms of what does not become organized, but we also wish to focus on the specific features of such achievements, through a further understanding of issues of repetition and alterity. Is it possible to reconceive these apparently irreconcilable dichotomies within an alternative heuristic. This includes rethinking the object as emerging from a process of attracting diversity, which paradoxically enables it to exist through difference and repetition, and not as a fixed, independent and immutable entity, or one constructed or known merely through multiple interpretations.

\section{NOTES}

\footnotetext{
${ }^{1}$ Further developed by Deleuze.

${ }^{2}$ http://meetings.aomonline.org/2005/DivisionDomains.html\#CMS - accessed May 12, 2005.

${ }^{3}$ Thus, both size and durability are an outcome of these continual processes and struggles, and links to the idea that the more connections that underlie assemblages, the more real they are, but there is also greater potential vulnerability.
}

\section{REFERENCES}

Ackroyd, S. (2004). Less bourgeois than thou? A critical review of studying management critically. Ephemera: Theory \& Politics in Organization, 4(2), 165-170.

Adler, P. (2002). Critical in the name of whom and what? Organization, 9(3), 387-395.

Alvesson, M., \& Willmott, H. (1992b). Critical management studies. London: Sage.

Alvesson, M., \& Willmott, H. (1992a). On the idea of emancipation in management and organization studies. Academy of Management Review, 17(3), 432-464.

Alvesson, M., \& Willmott, H. (1996). Making sense of management. London: Sage.

Armstrong, P. (2001). Styles of illusion. The Sociological Review, 49(2), 155-171.

Bijker, W., \& Law, J. (1992). Shaping technology/building society: studies in sociotechnical change. London: MIT Press. 
Boje, D., Böhm, S. G., Casey, C., Clegg, S., Contu, A., Costea, B., Gherardi, S., Jones, C., Knights, D., Reed, M., Spicer, A., \& Willmott, H. (2001). Radicalising organisation studies and the meaning of critique. Dialogue. Ephemera, 1(3), 303-313.

Callon, M. (1986). Some elements of a sociology of translation - domestication of the scallops and the fishermen of st-brieuc bay. Sociological Review Monograph, 4(2), 196-233.

Callon, M., \& Law, J. (2004). Introduction: absence - presence, circulation, and encountering in complex space. Environment and planning d- space and society, 22(1), 3-11.

Collinson, D. (2002). Response - Shop floor. Organization, 9(1), 41-50.

Czarniawska, B. (2004). Gabriel tarde and big city management. Distinktion, 9, 81-95.

De Laet, M., \& Mol, A. (1998). The zimbabwe bush pump: machines of a fluid technology. Social Studies of Science, 30(2), 225-263.

Fournier, V., \& Grey, C. (2000). At the critical moment: conditions and prospects for critical management studies. Human Relations, 53(1), 7-32.

Gormat, E., \& Hennion. A. (1999). A sociology of attachment: music amateurs, drug users. In J. Law \& J. Hassard (Coords.). Actor Network Theory and After. Oxford: Blackwell.

Gramsci, A. (1971). Selections from the prison notebooks. New York: International.

Grey, C. (2005). Critical management studies: towards a more mature politics. International Critical Management Studies Conference. Cambridge, 4.

Hardt, M., \& Negri, A. (2000). Empire. Cambridge, Mass: Harvard University Press.

Hassard, J., Hogan, J., \& Rowllinson, M. (2001). From labour process to critical management studies. Administrative Theory \& Praxis, 23(3), 339-362.

Hetherington, K. (2004). Secondhandedness: consumption, disposal and absent presence. Envoironment and Planning D: Society and Space, 22(1), 157-173.

Hetherington, K., \& Lee, N. (2000). Social order and the blank figure. Envoironment and Planning D: Society and Space, 18(2), 169-184.

Jermier, J. M. (1994). Critical issues in organizational science: a dialogue. Organization Science, 5(1), $1-12$.

Jones, G., Mclean, C., \& Quattrone, P. (2004). Spacing and Timing. Organization, 11(6), 723-741.

Knights, D. (2002). Writing organizational analysis into foucault. Organization, 9(4), 575-593.

Latour, B. (1982). Give me a laboratory and I will move the world. In K. Knorr \& M. Mulkay (Eds.). Science observed. London: Sage.

Latour, B. (1988). Mixing humans with non-humans: sociology of door closer. Social Problems, 35(3), 298-310.

Latour, B. (1991). Technology is society made durable. In J. Law (Ed.). Sociology of monsters: essays on power, technology and domination. London: Routledge. 
Latour, B. (1992). Where are the missing masses? The sociology of a few mundane artefacts. In W. Bijker \& J. Law (Eds.). Shaping technology/building society: studies in sociotechnical change. London: MIT Press.

Latour, B. (1993). We have never been modern. New York: Harvester Wheatsheaf.

Latour, B. (1997). Trains of thought Piaget, formalism and the fifth dimension. Common Knowledge, 6(3), 170-191.

Latour, B. (1999). On recalling ANT. In J. Law \& J. Hassard (Eds.). Actor network theory and after. Oxford: Blackwell.

Latour, B. (2001). Gabriel Tarde and the end of the social. Soziale Welt-Zeitschrift Fur Sozialwissenschaftliche Forschung Und Praxis, 52(3), 361-372.

Latour, B. (2002). What is iconoclash? Or is there a world beyond the image wars? Introduction to the catalog of the exhibit Iconoclash. In P. Weibel \& B. Latour (Eds.). Beyond the Image-Wars in Science, Religion and Art. Cambridge: MIT Pess, \& ZKM.

Latour, B. (2003). The powers of fax smiles. A turing test on science and literature. Retrieved August 13, 2005, from http://www.bruno-latour.fr/articles/article/94-POWERS-TURING.pdf

Latour, B. (2004). Whose cosmos, which cosmopolitics? Comments on the peace terms of ulrich beck. Common Knowledge,10(3), 450-452.

Latour, B. (2005). Reassembling the social: an introduction to actor-network-theory. Oxford: Oxford University Press.

Law, J. (1991). Introduction: monsters, machines and sociotechnical relations. In J. Law (Ed.). Sociology of monsters: essays on power, technology and domination. London: Routledge.

Law, J. (1992). Notes on the theory of the Actor-Networking: ordering, strategy and heterogeneity. Centre for Science Studies, Lancaster University, Lancaster LA1 4YN, at. Retrieved February 21, 2006, from http://www.comp.lancs.ac.uk/sociology/papers/Law-Notes-on-ANT.pdf

Law, J. (1999a). After ANT: complexity, naming and topology. In J. Law \& J. Hassard (Eds.). Actor network theory and after. Oxford: Blackwell.

Law, J. (1999b). Objects, spaces and others. Centre for Science Studies. Lancaster University, Lancaster LA1 4YN, UK, at. Retrieved February 21, 2006, from http://www.lancs.ac.uk/sociology/papers/Law-Objects-Spaces-Others.pdf

Law, J. (2004). After method: mess in social research. London: Routledge.

Law, J., \& Mol, A. (2000). Situating techoscience: an inquire into spatialities. Centre for Science Studies. Lancaster University, Lancaster LA1 4YN, UK, at. Retrieved April 23, 2003, from http://www.comp.lancs.ac.uk/sociology/papers/Law-Mol-Situating-Technoscience.pdf

Law, J., \& Moser, I. (1999). Managing, subjectivities and desires. Centre for Science Studies. Lancaster University, Lancaster LA1 4YN, UK, at. Retrieved February 21, 2006, from http://www.comp.lancs.ac.uk/sociology/papers/Law-Moser-Managing-Subjectivities-desires.pdf

Law, J., \& Singleton, V. (2005). Object lessons. Organization, 12(3), 331-355.

Lee, J., \& Hassard, J. (1999). Organization unbound: actor-network theory, research strategy and institutional flexibility. Organization, 6(3), 391-404. 
McLean, C., \& Hassard, J. (2004). Symmetrical absence/symmetrical absurdity: critical notes on the production of actor network accounts. Journal of Management Studies, 14(3), 493-519.

Organization (2005). Special Issue on Critical Management Studies, 9(3), 365-385.

Parker, M. (1999). Capitalism, subjectivity and ethics: debating latour process analysis. Organization Studies, 20(1), 24-45.

Parker, M. (2002). Against management. Oxford: Polity.

Shayne, G., \& Humphries, M. (1997). Critical management studies in postmodernity: oxymorons in outer space? Journal of Organizational Change, 10(5), 412-422.

Thompson, P. (1983). The nature of work. London: McMillan.

Thompson, P. (2004). Brands, boundaries and bandwagons: a critical reflection on critical management studies. In S. Fleetwood \& S. Acroyd (Eds.). Critical realism in action in organsiation and management studies. London: Routledge.

Willmott, H. (1995). What has been happening in organization theory and does it matter? Personnel Review, 24(8), 33-49.

Wray-Bliss, E. (2002). Abstract ethics, embodied ethics: the strange marriage of foucault and positivism in labour process theory. Organization, 9(1), 5-39.

Zald, M. (2002). Spinning disciplines: critical management studies in the context of the transformation of management education. Organization, 9(3), 365-385. 